\title{
Investigation of Catalyst Projects and Urban Design Qualities in Six Central Streets of Hamedan
}

\begin{abstract}
Streets are like a vein in the body and play an important role in whole cities. These crucial elements are so essential in each cities structure. The primary roots of the system can quickly figure out by the distribution of city streets. So central streets are more critical than the peripheral ones because more users refer to them. Hamedan is a mountainous city in the west of Iran, which is shape by circles form. This unique structure is exceptional in Iran and is based on the main square and its six streets. This paper tries to figure out the differences between this street, catalyst intervention, and cardriven streets. Also, comparing these two types of streets and their results can help urban management and city responsible. Catalyst projects are some intervene that seek to inject new spirit in target areas. These actions are trying to respond to further people's needs based on the context's general identity. The research methodology is quantitative based on ANP techniques to specify these six streets' priorities and interpret differences between catalysts projects and cars-driven streets. So, the results show that two streets among six central streets are more acceptable in users' mindsets. Bu Ali st and Ekbatan st have high normalized points than other streets. Besides, users can easily walk all the parts of these two streets, perform window shopping, sit wherever they want, and do all kinds of group and individual activities. These consequences have more overlapping with two streets that have been intervened by catalyst actions, and their roles transformed into walkable instead of car-driven streets.
\end{abstract}

Keywords: Catalyst projects, Urban design qualities, Central streets, Hamedan.

\section{Introduction}

Increasing urban design qualities are essential issues in cities, especially in primary elements like squares and streets. Streets play a crucial role in whole structured towns, and improving their qualities can lead them to grow better. Catalyst projects are an appropriate anchor to perform this quality as well as possible. This approach is so keen on target areas and the surrounding environment of its intervene. This research aims to figure out the differences in streets where catalytic reactions occurred and their other central car-driven streets. The main question is that does any catalytic reactions improve the circumstances of the six central streets of Hamedan? And do these changes are overlapping in users of spaces' mindsets?

The importance of these questions can make urban managers the right decision about the urban spaces in a bright future. 
ISAHP Article: A Style Guide for Paper Proposals To Be Submitted to the International Symposium on the Analytic Hierarchy Process 2020, Web Conference.

\section{Literature Review}

Many scientists study urban design qualities, and some of the importance of this include the indicators of this paper. Also, vitality, traffic issues, functional dynamics, compatibility, and flexibility are critical points of the research interview and observations.

Catalyst projects are the latest approach to improve all types of urban environments. This approach has been changed from giant projects to small-scale urban design projects, which increase social interaction and cultural prosperity in urban spaces.

\section{Hypotheses/Objectives}

It seems that improving qualities by catalyst projects in central parts of cities can provide better urban life for citizens.

\section{Research Design/Methodology}

This research methodology is based on a quantitative method that is performed by ANP techniques. The model came from a literature review and indicators derived from the study of research keywords. Then, for more accuracy, the indicators are divided into subindicators to investigating the alternatives better. Also, the judgments were obtained by interviews and field observation of the case study. Moreover, the users' common attitude has formed the assessment of goal, criteria, and alternatives in the research model. Besides, the inconsistency is less than 0.1 in all comparisons.

\section{Data/Model Analysis}

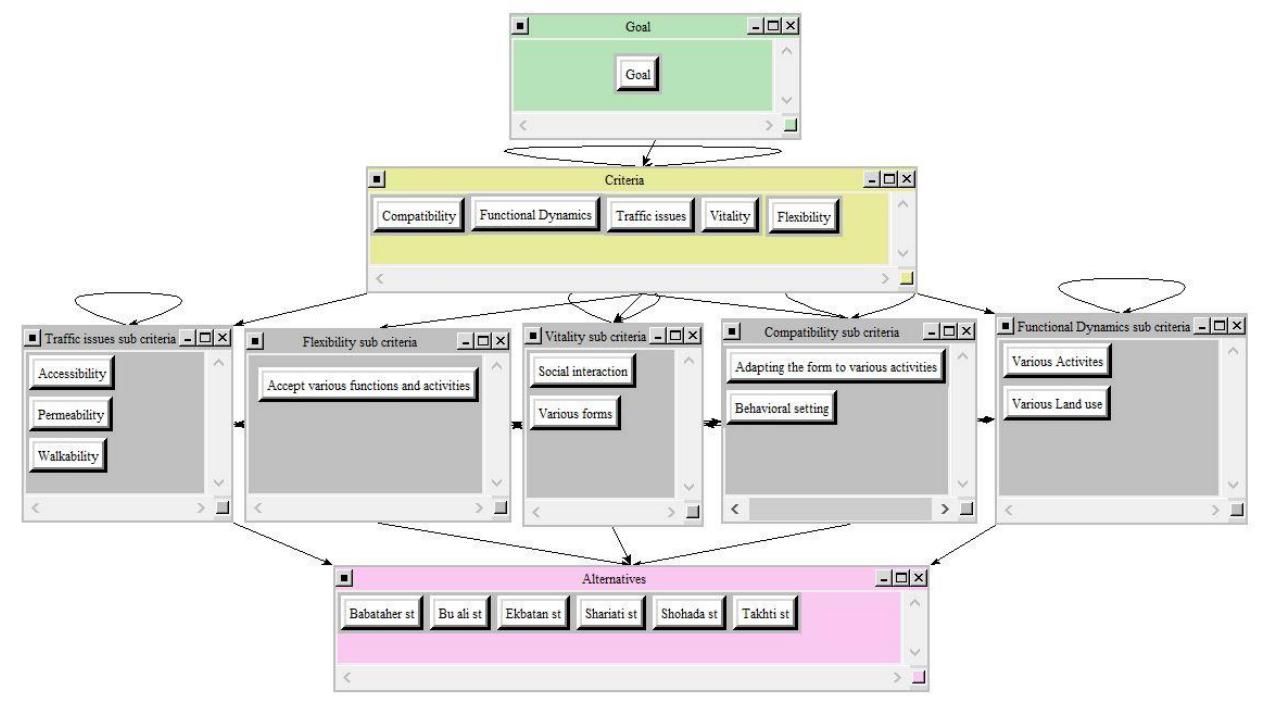

\section{Limitations}

Figure 1; the model analysis of this study.

Due to the covid-19 pandemic, the interviews and observation were faced with some troubles. The researchers control the process of study because the case study were such crowded and populated spaces.

International Symposium on the 
ISAHP Article: A Style Guide for Paper Proposals To Be Submitted to the International Symposium on the Analytic Hierarchy Process 2020, Web Conference.

\section{Conclusions}

$\mathrm{Bu}$ Ali and Ekbatan streets are the first and second priorities in ANP model analysis compatible with the theoretical paper concept. The people's mindsets approve that the catalyst anchor may increase the cities elements qualities and grow it well. This study contributes for the first time using the ANP method to specify urban elements' rates through the urban catalyst field. Besides, urban management can easily find the right way to improve cities' cores.

\section{Key References}

Bohannon, C. L. (2004). The Urban Catalyst Concept (Doctoral dissertation, Virginia Tech).

Overmeyer, K., \& Misselwitz, P. (2011). Urban catalyst: Strategies for temporary use. P. Oswalt (Ed.). Basel: Birkhäuser.

$\mathrm{Mu}$, E. (2006). A unified framework for site selection and business forecasting using ANP. Journal of Systems Science and Systems Engineering, 15(2), 178-188.

Saaty, T.L., \& Peniwati, K. (2007). Group decision-making: Drawing out and reconciling differences. Pittsburgh, PA: RWS Publications.

Saaty, T.L., \& Shang, J.S. (2007). Group decision-making: Head-count versus intensity of preference. Socio-Economic Planning Sciences, 41, 22-37.

\section{Appendices}

\begin{tabular}{|c|c|c|c|}
\hline \multicolumn{4}{|c|}{ Here are the priorities. } \\
\hline Icon & Name & Normalized by Cluster & Limiting \\
\hline No Icon & Babataher st & 0.09170 & 0.015795 \\
\hline No Icon & Bu ali st & 0.39159 & 0.067453 \\
\hline No Icon & Ekbatan st & 0.22674 & 0.039057 \\
\hline No Icon & Shariati st & 0.13410 & 0.023099 \\
\hline No Icon & Shohada st & 0.09344 & 0.016095 \\
\hline No Icon & Takhti st & 0.06243 & 0.010754 \\
\hline No Icon & $\begin{array}{l}\text { Adapting the form to } \\
\text { various activities }\end{array}$ & 0.42673 & 0.073506 \\
\hline No Icon & Behavioral setting & 0.57327 & 0.098747 \\
\hline No Icon & Compatibility & 0.00000 & 0.000000 \\
\hline No Icon & Flexibility & 0.00000 & 0.000000 \\
\hline No Icon & Functional Dynamics & 0.00000 & 0.000000 \\
\hline No Icon & Traffic issues & 0.00000 & 0.000000 \\
\hline No Icon & Vitality & 0.00000 & 0.000000 \\
\hline No Icon & $\begin{array}{l}\text { Accept various functions } \\
\text { and activities }\end{array}$ & 1.00000 & 0.138733 \\
\hline No Icon & Various Activites & 0.41385 & 0.071288 \\
\hline No Icon & Various Land use & 0.58615 & 0.100966 \\
\hline No Icon & Goal & 0.00000 & 0.000000 \\
\hline No Icon & Accessibility & 0.19041 & 0.032798 \\
\hline No Icon & Permeability & 0.33926 & 0.058438 \\
\hline No Icon & Walkability & 0.47034 & 0.081017 \\
\hline No Icon & Social interaction & 0.43551 & 0.075018 \\
\hline No Icon & Various forms & 0.56449 & 0.097235 \\
\hline
\end{tabular}

Figure 2; ANP analysis priorities.

International Symposium on the 3 
ISAHP Article: A Style Guide for Paper Proposals To Be Submitted to the International Symposium on the Analytic Hierarchy Process 2020, Web Conference.

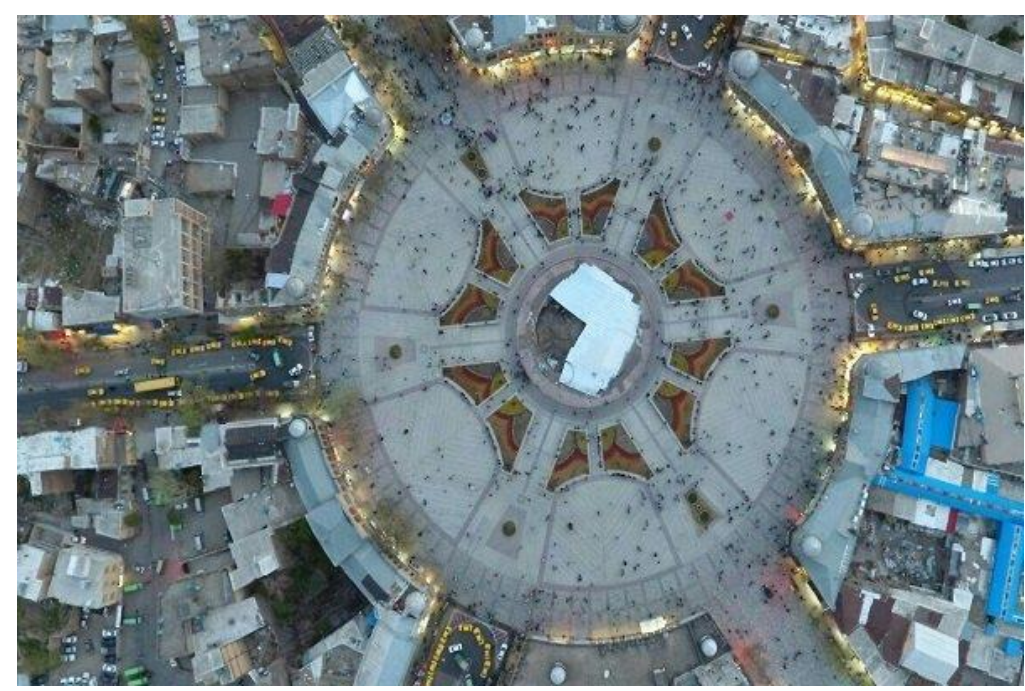

Figure 3; six central streets of Hamedan.

\begin{tabular}{|c|c|c|c|c|}
\hline Name & \multirow[t]{2}{*}{ Graphic } & Ideals & Normals & Raw \\
\hline Babataher st & & 0.234163 & 0.091696 & 0.015795 \\
\hline Bu ali st & & 1.000000 & 0.391589 & 0.067453 \\
\hline Ekbatan st & & 0.579031 & 0.226742 & 0.039057 \\
\hline Shariati st & & 0.342452 & 0.134101 & 0.023099 \\
\hline Shohada st & & 0.238619 & 0.093441 & 0.016095 \\
\hline Takhti st & & 0.159430 & 0.062431 & 0.010754 \\
\hline
\end{tabular}

Figure 4; ANP alternatives.

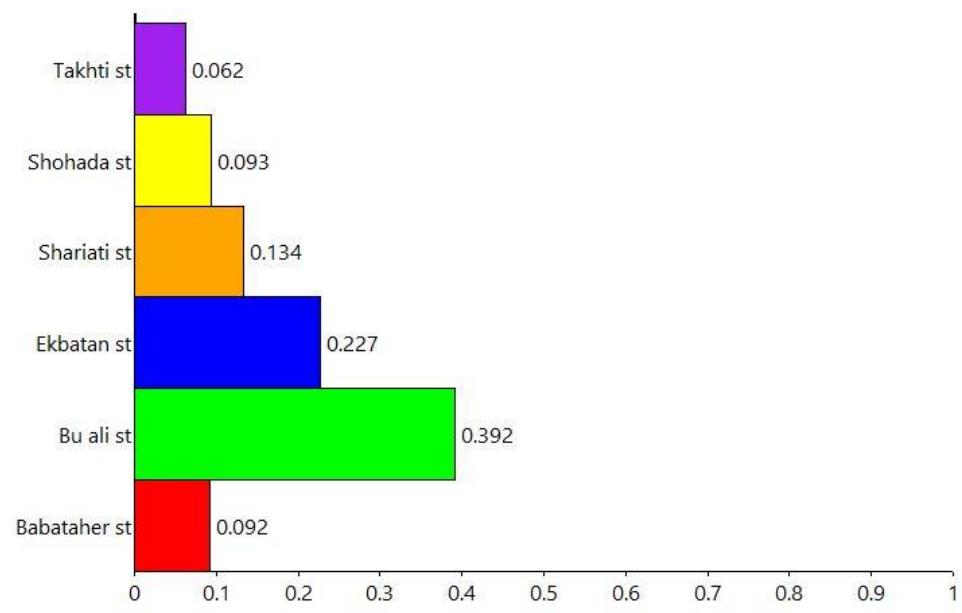

Figure 5; alternative bar chart. 
ISAHP Article: A Style Guide for Paper Proposals To Be Submitted to the International Symposium on the Analytic Hierarchy Process 2020, Web Conference.

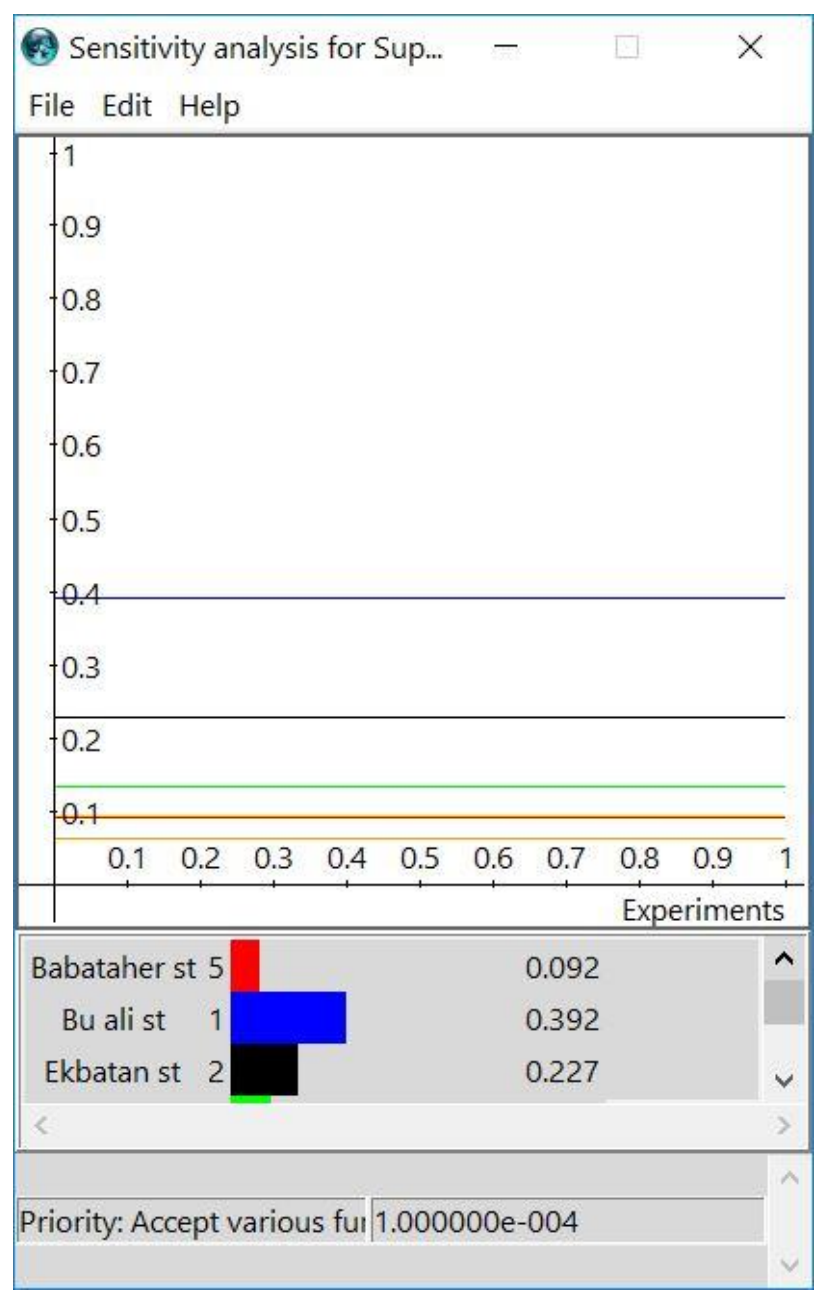

Figure 6; sensitivity analysis. 